\title{
Repair of critical size rat calvarial defects using endometrial-derived stem cells embedded within gelatin/apatite nanocomposite scaffold
}

\author{
Jafar $\mathrm{Ai}^{1,2,3,4^{*}}$, Saeed Heidari-Keshel ${ }^{5}$, Mahmoud Azami ${ }^{1}$, Armin $\mathrm{Ai}^{6}$, Naghmeh Bahrami ${ }^{1}$, \\ Abodoreza Mohamadnia ${ }^{7}$ \\ ${ }^{1}$ Department of Tissue Engineering, School of Advanced Technologies in Medicine, Tehran University of Medical Sciences, Tehran, \\ Iran; *Corresponding Author: jafar_ai@tums.ac.ir \\ ${ }^{2}$ Research Center for Science and Technology in Medicine, Tehran University of Medical Sciences, Tehran, Iran \\ ${ }^{3}$ Brain and Spinal Injury Research Center, Tehran University of Medical Sciences, Tehran, Iran \\ ${ }^{4}$ Cellular and Molecular Research Center, Tehran University of Medical Sciences, Tehran, Iran \\ ${ }^{5}$ Clinical Proteomics Research Center, Faculty of Paramedical Sciences, Shahid Beheshti University of Medical Sciences, Tehran, \\ Iran \\ ${ }^{6}$ Faculty of Dentistry, Tehran University of Medical Sciences, Tehran, Iran \\ ${ }^{7}$ Department of Molecular Medicine, Hamedan University of Medical Sciences, Hamedan, Iran
}

Received 1 November 2012; revised 2 December 2012; accepted 3 January 2013

\begin{abstract}
Human stromal stem cells derived from endometrium (hESCs) are a type of multipotent stromal cells of the proven ability to differentiate into osteogenic lineage. Thus, it was suggested that these cells may be used to repair skeletal defects. In this study, Human ESCs were extracted from female endometrium and harvested. Biomimetic gelatin/apatite (Gel/Ap) scaffolds with and without harvested cells were implanted in a Critical size calvarial defects in the cranial bone of adult male rat. To CT-Scan and Histological studies were performed to investigate the level of bone formation after 8 weeks of surgery. Results confirmed that the treated defects with the bare and hESCs grafted Gel/Ap scaffold showed significant bone formation and maturation in comparison with the control group.
\end{abstract}

Keywords: Biomimetic Scaffold; Bone

Regeneration; Calvarial Defect; CT-Scan

\section{INTRODUCTION}

Autogrft and allograft transplantation are known as current strategies for the healing of skeletal tissues. Although these approaches were successful but they have shown some intrinsic limitations. For example, alloplastic materials have problems with rejection, infection and breakage. Limitation in availability, requirement for background operation and potential morbidity are known as clinical problems for the autologous tissue such as bone and bone marrow transplants [1,2]. Thus, need for other alternatives instead of currently available techniques for the repair of bone tissue still remains. Our laboratory has focused on the use of osteogenic ability of the endometrial mesenchymal stem cells for the repair of skeletal defects [3]. Mesenchymal stromal cells (MSCs) are multipotent undifferentiated cells possessing self-renewal capacity and potential for differentiation into various cell lines [4]. It is well established that adult mesenchymal stem cells constitute a reservoir located in the connective tissues of many organs whose biological function are involved in the regeneration and maintenance of tissues within whole postnatal life of an individual. In recent years, we and others have shown that menstrual blood, endometrium and fallopian tubes are very rich sources of mesenchymal stem cells and can differentiate into different cell lines in vitro and/or in vivo [5,6]. The unique ability to regenerate the human endometrium after menstruation, after childbirth, surgery (curettage, endometrial ablation) and postmenopausal women receiving hormone replacement therapy suggests that MSC niches in the present tissue are responsible, at least in part, by this process. it is believed that the human endometrium may include a significant number of stem cells that are responsible for endometrium remarkable regeneration ability [7]. It is the reason that makes hESC cells as a very interesting source for using in regenerative medicine studies, particularly in autoimmune diseases. In recent studies, adult mesenchymal stem cells [8] and side-population cells obtained from endometrial tissues hysterectomy have been identified in normal conditions [9]. In 
the study by Schwab and Gargett, endometrial mesenchymal stem cells were differentiated into mesodermderived lineages, including chondrogenic, adipogenic, osteogenic and myogenic lineages in vitro [8]. Moreover, a well-designed study by Hida and colleagues have shown that the mesenchymal cells derived from menstrual blood began spontaneously beating after being induced with specific action potentials of cardiomyocytes [10]. Also, Meng et al. could isolate a stem cell-like cells from menstrual blood which were called as regenerative "endometrial Cell" and were able to differentiate into nine lines, including pancreatic lineage that have been stained positively for insulin [11]. Although, the ability of the regenerative endometrial cells to differentiate into endodermal tissues and in connection with its putative endometrial mesenchymal stem cells are still poorly understood. In this study we aim to evaluate the ability of bone formation in a default mouse cranial critical size defect treated by a Gel/AP biomimetic scaffold incorporated with hESCs as a cell/scaffold construct.

\section{MATERIALS AND METHODS}

\subsection{Scaffold Preparation}

Porous GEL/AP nanocomposites were fabricated as follow: at first, gelatin (Merck, microbiology grade, catalogue number 104070) was added to deionized water, making a $10 \%(\mathrm{w} / \mathrm{v})$ solution. Hydroxymethy-laminomethane (Tris) (Merck, catalogue number 8382) and hydrochloric acid (HCl) (Merck, catalogue number 280211) were added to solution to prepare a buffer gel solution adjusted to $\mathrm{pH}$ 7.4. Disodium hydroxide phosphate (1 M) (Merck, catalogue number 106573) and calcium chloride (0.6 M) (Merck, catalogue number 2380) were prepared and the $\mathrm{pH}$ of both solutions were brought to about 7.4 using Tris and HCL. In the next step, the GEL-Calcium containing solution was poured into a cylindrical mold and kept at $4^{\circ} \mathrm{C}$ for 2 hours until physical gelatin occurred. Afterward, gel was extracted and soaked into the phosphate containing solution and incubated at $4^{\circ} \mathrm{C}$ for about 48 hours. Following diffusion of ions into the gel, a white precipitate formed within the gel in a gradient manner from the border to the center of gel. The resulting nanocomposite was extracted and freeze dried to create a porous structure through solvent sublimation. Scaffolds were incubated in a $1 \%$ glutaraldehyde (GA) (Merck, Catalogue number 820603) solution for 24 hours. Samples were washed with deionized water to remove remnants of the GA.

\subsection{Scanning Electron Microscopy (SEM)}

The morphology of the nanocomposites was assessed by scanning electron microscopy (SEM; Philips XL30 microscope). The images were obtained using an accel- erating voltage of $15 \mathrm{kV}$. All samples were coated with a gold sputtering device (EMITECH K450X, England) before being investigated under the scanning electron microscope. The obtained images were also used to evaluate the pore size of the nanocomposites.

\subsection{Endometrial Stem Cell (hESCs) Isolation and Culture}

The endometrium derived from stem cells isolation and culture were obtained from a biopsy sample of the endometrium collected during the phase of proliferation of a fertile of 26 years woman who had not undergone a hormonal exogenous treatment during at least 3 months before surgery. Informed consent was obtained and approval was granted by the ethics committee of the University of Tehran of Medical Sciences. The sample was taken in buffered HEPES Dulbecco Modified Eagle Medium/Hams F-12 (DMEM/F-12; Invitrogen ${ }^{\circledR}$ ) or DMEM glucose high (DMEM/High; Invitrogen ${ }^{\circledR}$ ) supplemented with $10 \%$ fetal bovine serum (FBS; Invitrogen ${ }^{\circledR}$ ), stored at $4^{\circ} \mathrm{C}$. and treated within $24 \mathrm{~h}$. The sample was washed twice in buffer saline phosphate (PBS), finely chopped with a (scalpel and placed in a Falcon tube $15 \mathrm{ml}$ and incubated in $10 \mathrm{ml}$ of collagenase Worthington ${ }^{\circledR}$ ) for 45 $\min$ at $37^{\circ} \mathrm{C}$ in a water bath. The supernatant was eliminated with a pipette Pasteur sterile, washed once with 7 $\mathrm{ml}$ of DMEM/F-12 supplemented with FBS to $10 \%$ in 15 $\mathrm{ml}$ of a hawk, and sedimented by centrifugation at $400 \mathrm{~g}$ for $5 \mathrm{~min}$ at temperature ambient. Cells were then plated in DMEM/F-12 (5 ml) supplemented with 10\% FBS, 100 $\mathrm{IU} / \mathrm{ml}$ penicillin (Invitrogen ${ }^{\circledR}$ ) and $100 \mathrm{IU} / \mathrm{ml}$ streptomycin (Invitrogen $\left.{ }^{\circledR}\right)$ in vials plastic $\left(25 \mathrm{~cm}^{2}\right)$, and maintained in a humidified atmosphere of $5 \% \mathrm{CO}_{2}$ in air at $37^{\circ} \mathrm{C}$. The culture medium used for the development was first changed every $72 \mathrm{~h}$ and regularly replaced twice by week thereafter.

\subsection{Imunophenotyping of hESCs}

The hESCs were first trypsinized and counted. Tubes containing about $1 \times 10^{6}$ cells were incubated on a rocking and centrifuged at $300 \mathrm{~g}$ for 6 minutes, then $2 \%$ human serum added to the repository. Mixtures resulted remained at room temperature for 30 minutes and centrifuged again as above. In addition to the PBS was added to the repository. The cell mixture was passed through a nylon mesh, $100 \mathrm{pl}$ of the mixture was added to each tube with the following antibodies: anti-CD105, anti-CD73, anti-CD45, anti-CD166, anti-CD90 and anti-CD34 (all products Abcam). In addition, these tubes were incubated at $4^{\circ} \mathrm{C}$ in a dark room for 45 minutes. After the washing process, the cells were fixed in 100 ul of $1 \%$ paraformaldehyde. Finally, flow cytometric analysis was performed. The ratios of fluorescence signals from scattered 
signals were calculated by the flow cytometer (Partec). Histograms were generated using the software WinDmi 2.9.

\subsection{Seeding of Cells and Study of Cell Survival by MTT Assay}

After two passages, when the cells (hESCs) reached almost confluence completely, then they were digested with $0.25 \%$ trypsin/EDTA (Gibco), counted and seeded on scaffolds at a density of $1 \times 10^{5}$ cells $/ \mathrm{ml}$ in plate wells 6 -flat bottom. The samples were sterilized by exposure to UV light for 2 hours on both sides facing cell seeding. Cultures were maintained in an incubator at $37^{\circ} \mathrm{C}$ in an atmosphere of $5 \% \mathrm{CO}_{2} / 95 \%$ air, and the cell culture medium was changed every 3 days. The MTT assay is a rapid color to determine the number of viable cells, which is based on the mitochondrial conversion of MTT to formazan. Briefly, the cell containing the sample was rinsed with serum-free medium to remove cells only 200 $\mu \mathrm{l}$ and serum-free medium and $20 \mu \mathrm{l}$ of MTT stock solution (5 mg/ml in RPMI 1640) were added to each sample and incubated for $4 \mathrm{~h}$ (37 c) MTT fomarazan training. After adding $200 \mu \mathrm{l}$ of DMSO solution was used for the density (OD) measurement with optical absorbance detection microplate reader at $570 \mathrm{~nm}$ (Rayeto, USA).

\subsection{Multilineage Cell Differentiation: Induced Differentiation of hESCs into Adipogenic, Chondrogenic and Neuronal Cells}

Adipogenic differentiation: $1 \times 10^{5} \mathrm{hESCs}$ of the 5th to 8th passages were treated with adipogenic medium for 14 days. Adipogenic medium consisted of IMDM supplemented with $0.5 \mathrm{mmol} / \mathrm{L}$ 3-isobutyl-1-methylxanthine (Sigma-Aldrich), $1 \mathrm{~mol} / \mathrm{L}$ hydrocortisone (Sigma-Aldrich), $0.1 \mathrm{mmol} / \mathrm{L}$ indomethacin (Sigma-Aldrich), and rabbit serum 10\% (Sigma-Aldrich). For the evaluation of adipocytes, cells were fixed with $4 \%$ formaldehyde and stained with oil red O (Sigma).

Osteogenic differentiation: $1 \times 10^{5} \mathrm{hESCs}$ of the 5th to 8th passages were treated with osteogenic medium for 3 weeks. Osteogenic medium consists of DMEM-LG (Gibco) supplemented with $50 \mathrm{lg} / \mathrm{ml}$ ascorbate-2 phosphate, 10-8 dexamethasone, and $10 \mathrm{mM}$ b-glycerophosphate (all from Sigma, St. Louis, MO). Osteogenesis was assessed by staining with alizarin red. For the evaluation of the mineralized matrix, and induced hESCs were treated with silver nitrate $2 \%$ (Sigma) under UV radiation for $1 \mathrm{~h}$. The cells were fixed with sodium thiosulfate $2.5 \%$ (Sigma) for $5 \mathrm{~min}$ and washed in $\mathrm{dH}_{2} \mathrm{O}$. The cells were then stained with cons-1\% neutral red (Sigma) for 1 min (Chen et al.).

Neurogenic differentiation: $1 \times 10^{5}$ hESCs of the 5 th to 8th passages were treated with serum-free medium modified neurogenic selection for two weeks. Serum-free medium for the selection of neural precursor cells contained DMEM/F12 1:1 (Gibco) and was supplemented with $0.6 \%$ glucose, $25 \mathrm{pg} / \mathrm{ml}$ insulin, $100 \mu \mathrm{g} / \mathrm{ml}$ transferrin, $20 \mathrm{nM}$.

\subsection{Surgeries and Treatment Groups}

Twenty male Wistar rats with starting weight 200 $250 \mathrm{gr}$ were allowed to acclimatise for 7 days. They were maintained in individually ventilated cages at $23^{\circ} \mathrm{C} \pm 2^{\circ} \mathrm{C}$ with a 12:12 h light-dark cycle and food and water were provided ad libitum. The rats were anesthetized i.p. with a mixture of ketamine $(85 \mathrm{mg} / \mathrm{kg})$ and xylazine $(15 \mathrm{mg} /$ $\mathrm{kg}$ ) were fixed on the stereotax. Scalps were then shaved, shaved and prepared for surgery. The skull was exposed through an incision in the scalp midline, and the skin and periosteum are reflected laterally border ridges (Figure 1). Default monolateral $(n=10)$ were created in the parietal bones, using a $5 \mathrm{~mm}$ drill burr. Great care has been taken to ensure that the time was left intact because of its osteoinductive properties. The defects were randomly filled with one of two treatments: 1) Gel/Ap scaffold alone $(n=10), 2)$ the absence of treatment (default empty) $(n=6), 3)$ the endometrium Stem cells grown in Gel/Ap scaffolds $(n=10)$. The implants were held in place with components of the periosteum and the scalp incision was closed with sutures.

\subsection{Data Collection and Statistical Analysis}

8 weeks after surgery, all rats were euthanized by IV injection $(40 \mathrm{mg} / \mathrm{kg}$ ) of pentobarbital (Nembutal, Abbott Laboratories, North Chicago, IL) and the calvaria were harvested for radiographic and histologically. Radiographs were obtained by Faxitron (MX-20 X-Ray Faxitron Corporation, Chicago, IL). Radiographs were seen under a microscope Leica MZ12 Stereo Zoom and Northern Eclipse (v 5.0) software image analysis (Empix Imaging, Inc., Cheektowaga) was used to draw the perimeter of each defect and evaluate the total area. Means and standard deviations for fault zone were calculated and compared between groups using, One-way analysis of variance (ANOVA). All data were analyzed using SPSS 12.0 for Windows (SPSS Inc., Chicago, IL). Differences were considered significant if $\mathrm{P}$ value was less than 0.05 . The samples were then fixed in $10 \%$ buffered formalin neutral (Sigma), demineralized in EDTA (Sigma) solution, dehydrated in a series of washes alcohol and embedded in paraffin.

The samples were cut in the coronal plane at a thickness of $5-7 \mathrm{~m}$ and stained with hematoxylin and eosin for conventional qualitative analysis Light field optical microscopy. 


\section{RESULTS}

\subsection{Scanning Electron Microscopy (SEM)}

SEM was used to evaluate the morphology of the nanocomposites. Figure 1 shows images captured from the surfaces of prepared porous nanocomposite scaffolds with SEM. As shown in Figure 2, a network of interconnected pores with a fairly uniform honeycomb-like shape can be seen. These scaffolds have pore diameters ranging from 150 to $350 \mu \mathrm{m}$, which are optimal for bone cell growth. The formation of distributed clusters of precipitates, including spherical agglomerated nanoparticles within the GEL matrix could be observed from the taken micrographs.

\subsection{Viability of hES Cells}

The MTT results after 48 hours showed that $96 \%$ of hESCs are alive in the presence of Gel/Ap nanocomposite scaffold which confirms the biocompatibility of the prepared scaffold.

\subsection{CT-Scan}

The rats were anesthetized with a mixture of ketamine and xylazine and CT-Scan 3 tesla using Bone gread software was performed after 8 weeks of surgery to evaluate the rate of bone repair. The amount of healing, bone repair and their position for the group with scaffold only and the group with hESCs are shown in Figures 3(a) and (b). The whole defect was repaired in scaffold with hESCs (Figure 4).

\subsection{Histology}

Mild inflation was found in scaffold with hESCs (group 2). There was a moderate inflation in control group. The foreign body reaction did not report.

The woven and lamellar bones were observed in group 1 and 2, as lamellar bone was greater (Figures 5(a)-(c)).

The amount of new bone was significantly higher in group 2 compared with both group 1 and control ( $\mathrm{p}<$ 0.05) (Table 1).

\section{DISCUSSION}

The use of endosseous implants and metallic plates is firmly established in skeletal reconstructive surgery. Implants have been used with some success but sometimes revision surgery is needed. There are some complications due to the use of implants such as: pain [12], wear [13], metallic particles accumulation in tissues [14-19], hypersensitivity to titanium [15-17], interruption with radiotherapy and radiology [18-20], stress shielding, growth failure [21], infection and loosening of implants [22]. In

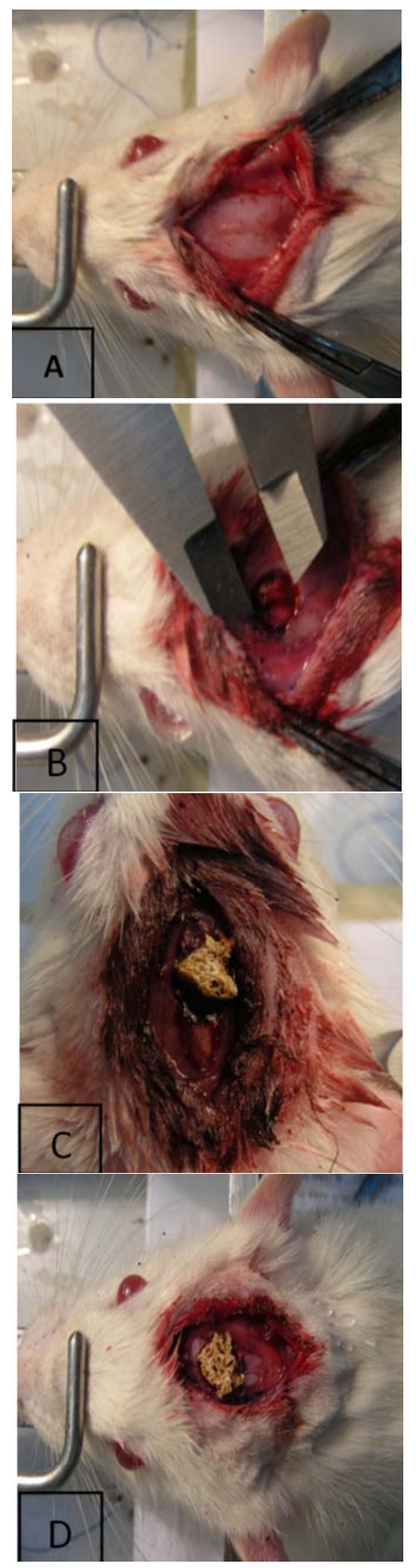

Figure 1. (A) Exposure of the calvaria; (B) Mono lateral critical-sized rat calvarial defect (full thickness bone skull defects); (C) Gel/Apatite scaffold implanted into calvarial defect; (D) Gel/Ap scaffold combination with endometrial stem cell, implanted into calvarial defect. 


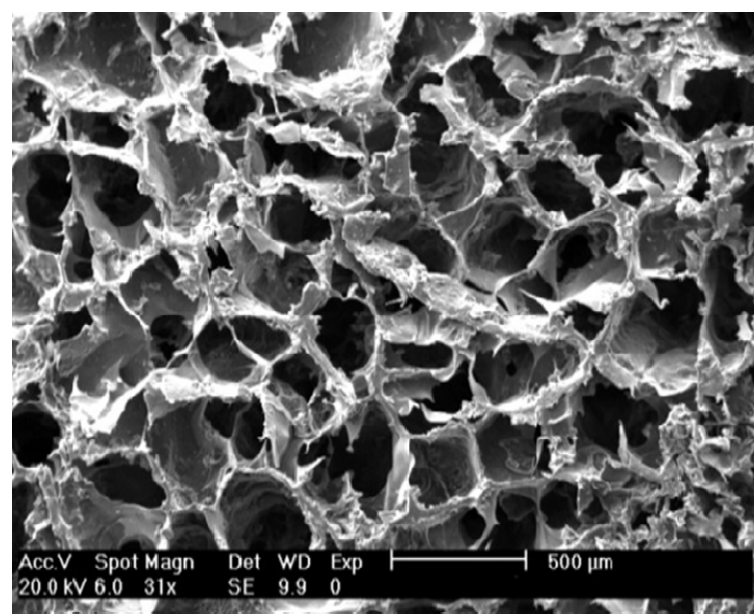

Figure 2. SEM micrograph of Gel/Ap scaffold.

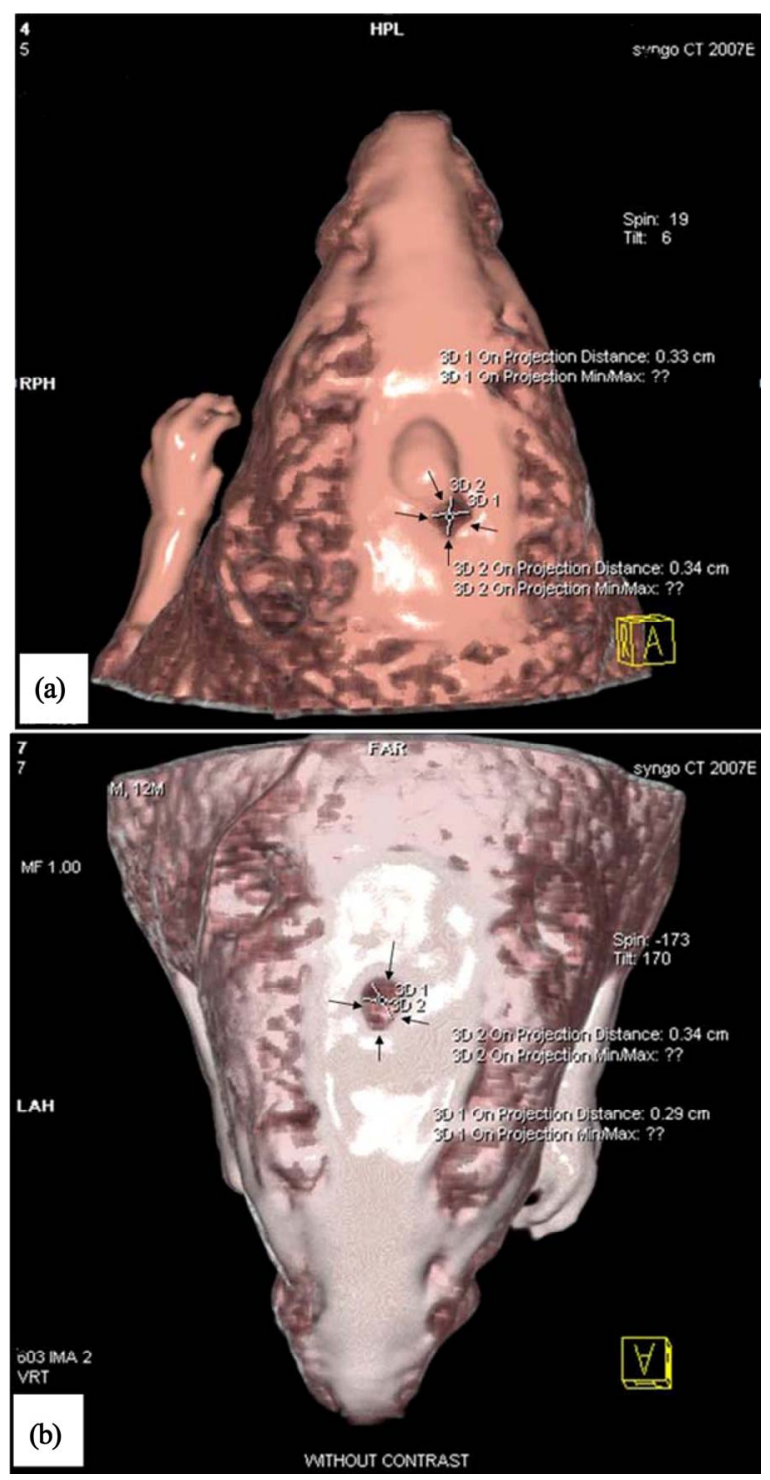

Figure 3. CT-Scan images of rat calvarial. (a) Scaffold only; (b) Scaffold with hESCs.

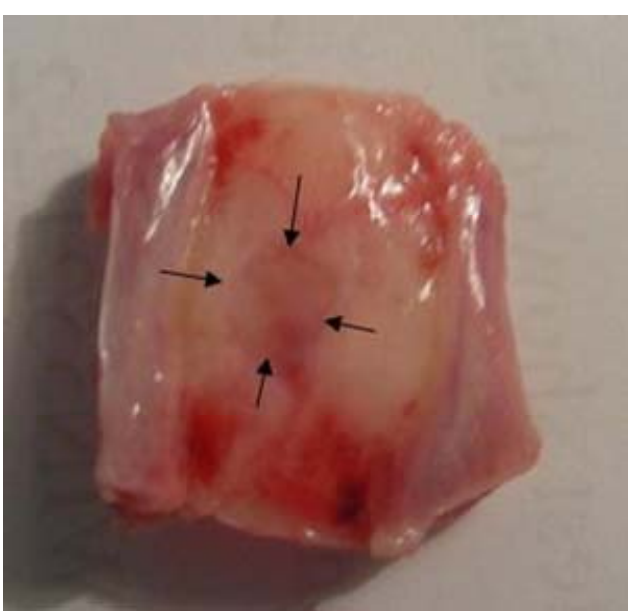

Figure 4. Digital camera image of complete repair of the rat calvarial after 8 weeks of surgery treated with scaffold containing hESCs.

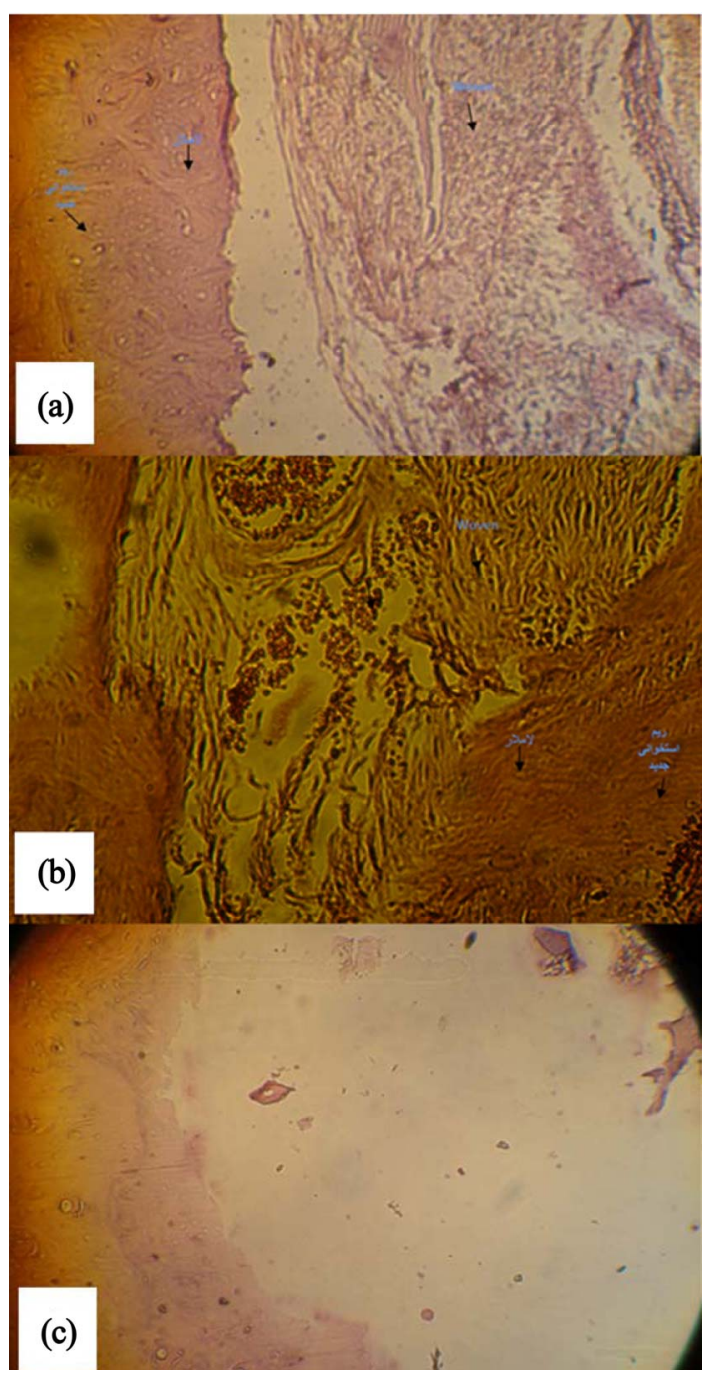

Figure 5. Light microscopy images show the amount of bone formation in the calvarial defect. (a) Scaffold only, (b) Scaffold with hESCs and (c) Control. 
Table 1. The amount of bone repair calculated using defect average dimension after repair for control, bare scaffold and scaffold with ESCs ( $<$ 0.05).

\begin{tabular}{cccc}
\hline Mice & $\begin{array}{c}\text { Bare } \\
\text { scaffold }(\mathrm{cm})\end{array}$ & $\begin{array}{c}\text { Scaffold with } \\
\text { hESCs }(\mathrm{cm})\end{array}$ & Control $(\mathrm{cm})$ \\
\hline 1 & $0.33,0.34$ & $0.29,0.34$ & $0.44,0.49$ \\
2 & $0.31,0.32$ & $0.25,0.26$ & $0.48,0.47$ \\
3 & $0.30,0.30$ & $0.27,0.25$ & $0.46,0.44$ \\
4 & $0.30,0.28$ & $0.22,0.24$ & $0.49,0.45$ \\
5 & $0.29,0.30$ & $0.23,0.25$ & $0.44,0.49$ \\
$\begin{array}{c}\text { Repair rate } \\
\text { (bone gread) }\end{array}$ & $62.57 \%$ & $74.08 \%$ & $13.69 \%$ \\
p value & $\mathrm{p}<0.05$ & $\mathrm{p}<0.05$ & $\mathrm{p}<0.05$ \\
\hline
\end{tabular}

order to prevent the mentioned complications biodegradable implants have drawn the attention. These types of implants could dissolve in the body and there is no need to remove them from the body [23]. Studies have shown that adult stem cells derived from bone marrow improves the healing process. Combing stem cells with implants and scaffolds using tissue engineering techniques provides a promising strategy to repair the bone fractures rapidly.

Here, hESCs have been used as a new source of stem cells. The endometrial cells have the high capacity to regenerate [24]. Studies have been shown that the human endometrium grows from $0.5-1 \mathrm{~mm}$ to $5-7 \mathrm{~mm}$ during the menstrual cycles. There are population of stem cells in the basal layer which have the ability to proliferate and migrate to the functional layer of the endometrium to regenerate this layer and these cells can differentiate to other cells such as endothelial cells, neuron, adipocyte, osteoblast and myoblast [25-31]. There are some bone disorders such as malunion and infections which cannot be healed spontaneously. These types of complications need to be treated by implants or bone transplantation. Bone resection surgeries are painful and cause the lesion which needs to be repaired. Furthermore, it may cause infection. Accumulation of harmful ions released from metallic implants may increase the risk of cancer [32-33].

The ability of mesenchymal stem cells to differentiate to bone cells has the potential to be used in cellular therapy in the treatment of bone related lesion. Some researchers believe that it is better to use differentiated cells in the cellular therapy rather than undifferentiated cells in order to prevent cells producing unwanted non-skeletal cells. In 2010, Azami et al. built hydroxyapatite-gelatin composite with about $82 \%$ porosity, compressive strength $2.2 \pm 0.5 \mathrm{MPa}$ and young modules $48.3 \pm 14 \mathrm{MPa}$. This is comparable with trabecular bone with the compressive strength of 2-12 Mpa [34]. Therefore, it can be assumed that the prepared scaffold in this work has almost proper mechanical properties.

\section{CONCLUSION}

This work demonstrates that Gel/Ap nanocomposit scaffold has the potential to use in the in the field of skeletal reconstructive surgery as a biodegradable nano-bio implant which is adaptable/non toxic with ESCs.

\section{ACKNOWLEDGEMENTS}

We thank Tehran University of Medical Sciences Research assistant, Iranian Council of Stem Cell Technology and Iran National Science Foundation (INSF) for financial supported.

\section{REFERENCES}

[1] Fang, T.D., et al. (2006) Guided tissue regeneration enhances bone formation in a rat model of failed osteogenesis. Plastic and Reconstructive Surgery, 117, 1177-1185. doi:10.1097/01.prs.0000204581.59190.53

[2] Chim, H. and Schantz, J.T. (2005) New frontiers in calvarial reconstruction: Integrating computer-assisted design and tissue engineering in cranioplasty. Plastic and Reconstructive Surgery, 116, 1726-1741. doi:10.1097/01.prs.0000182386.78775.cd

[3] Levi, B., James, A.W., Nelson, E.R., Vistnes, D. and Wu, B. (2010) Human adipose derived stromal cells heal critical size mouse calvarial defects. PLOS ONE, 5, e11177. doi:10.1371/journal.pone.0011177

[4] Dominici, M., et al. (2006) Minimal criteria for defining multipotent mesenchymal stromal cells. Cytotherapy, 8, 315-317. doi:10.1080/14653240600855905

[5] Jazedje, T., et al. (2009). Human fallopian tube: A new source of multipotent adult mesenchymal stem cells discarded in surgical procedures. Journal of Translational Medicine, 7, 46. doi:10.1186/1479-5876-7-46

[6] Gargett, C.E. (2007) Review article: Stem cells in human reproduction. Reproductive Sciences, 14, 405-424. doi:10.1177/1933719107306231

[7] Gargett, C.E. (2007) Uterine stem cells: What is the evidence? Human Reproduction Update, 13, 87-101. doi:10.1093/humupd/dml045

[8] Schwab, K.E. and Gargett, C.E. (2007) Co-expression of two perivascular cell markers isolates mesenchymal stemlike cells from human endometrium. Human Reproduction, 22, 2903-2911. doi:10.1093/humrep/dem265

[9] Tsuji, S., et al. (2008) side population cells contribute to the genesis of human endometrium. Fertility and Sterility, 90, 1528-1537. doi:10.1016/j.fertnstert.2007.08.005

[10] Hida, N., et al. (2008) Novel cardiac precursor-like cells from human menstrual blood-derived mesenchymal cells. Stem Cells, 26, 1695-1704. doi:10.1634/stemcells.2007-0826

[11] Meng, X., et al. (2007) Endometrial regenerative cells: A novel stem cell population. Journal of Translational Me- 
dicine, 5, 57-67. doi:10.1186/1479-5876-5-57

[12] Schmidt, B.L., Perrott, D.H., Mahan, D. and Kearns G. (1998) The removal of plates and screws after Le Fort I osteotomy. Journal of oral maxillofacial surgery, 56, 184-188. doi:10.1016/S0278-2391(98)90865-5

[13] Agins, H.J., et al. (1988) Metallic wear in failed titaniumalloy total hip replacements. A histological and quantitative analysis. The Journal of Bone \& Joint Surgery, 70, 347-356

[14] Schliephake, H., Reiss, G., Urban, R., Neukam, F.W. and Guckel, S. (1993) Metal release from titanium fixtures during placement in the mandible: An experimental study. The International Journal of Oral \& Maxillofacial Implants, 8, 502-511.

[15] Katou, I.F., Andoh, N., Motegi, K. and Nagura, H. (1996) Immuno-inflammatory responses in the tissue adjacent to titanium miniplates used in the treatment of mandibular fractures. Journal of Cranio-Maxillofacial Surgery, 24, 155-162. doi:10.1016/S1010-5182(96)80049-7

[16] Hunt, J.A., Williams, D.F., Ungersböck, A. and Perrin, S. (1994) The effect of titanium debris on soft tissue response Journal of Materials Science: Materials in Medicine, 5, 381-383. doi:10.1007/BF00058968

[17] Lalor, P.A., et al. (1991) Source Sensitivity to titanium. A cause of implant failure? The Journal of Bone \& Joint Surgery, 73, 25-28.

[18] Castillo, M.H., et al. (1988) Effects of radiotherapy on mandibular reconstruction plates. The American Journal of Surgery, 156, 261-263. doi:10.1016/S0002-9610(88)80287-3

[19] Sullivan, P.K., Smith, J.F. and Rozzelle, A.A. (1994) Cranio-orbital reconstruction: Safety and image quality of metallic implants on CT and MRI scanning. Plastic and Reconstructive Surgery, 94, 589-596. doi:10.1097/00006534-199410000-00004

[20] Brodke, D.S., et al. (2001) Dynamic cervical plates: Biomechanical evaluation of load sharing and stiffness. Spine, 26, 1324-1329.

[21] Yaremchuk, M.J. (1994) Experimental studies addressing rigid fixation in craniofacial surgery. Clinics in Plastic Surgery, 21, 517-524.

[22] Seipel, R.C., Schmeling, G.J. and Daley, R.A. (2001) Migration of a K-wire from the distal radius to the heart. American Journal of Orthopedics, 30, 147-151.

[23] Hofmann, G.O. (1995) Biodegradable implants in trau- matology: A review on the state-of-the-art. Archives of Orthopaedic and Trauma Surgery, 114, 123-132. doi:10.1007/BF00443385

[24] Gargett, C.E. (2007) Uterine stem cells: What is the evidence? Human Reproduction Update, 13, 87-101. doi:10.1093/humupd/dml045

[25] Lynch, L., Golden-Mason, L., Eogan, M., O’Herlihy, C. and O'Farrelly, C. (2007) Cells with haematopoietic stem cell phenotype in adult human endometrium: Relevance to infertility. Human Reproduction, 22, 919-926. doi:10.1093/humrep/del456

[26] Götte, M., et al. (2008) Increased expression of the adult stem cell marker Musashi-1 in endometriosis and endometrial carcinoma. The Journal of Pathologyl, 215, 317329. doi:10.1002/path.2364

[27] Ai, J., Esfandiari, N. and Casper, R. (2009) Detection of aromatase in human endometrial tissue cultured in threedimensional fibrin matrix in vitro. Iranian Journal of Reproductive Medicine, 7, 105-109.

[28] Ai, J., Noroozi, A. and Mehrabani, D. (2010) The Possibility of differentiation of human endometrial stem cells into neural cells. Iranian Journal of Reproductive Medicine, 12, 328-331.

[29] Ai, J., et al. (2012) Derivation of adipocytes from human endometrial stem cells (EnSCs). Journal of Reproduction and Infertility, 13, 151-157.

[30] Ai, J. and Mehrabani, D. (2010) The potential of human endometrial stem cells for osteoblast differentiation. Iranian Journal of Reproductive Medicine, 12, 585-587.

[31] Ai, J., Tabatabaei, F.S. and Kajbafzadeh, A.M. (2009) Myogenic potential of human endometrial adult stem cells. Iranian Journal of Medical Hypotheses and Ideas, 3, 3-6.

[32] Rah, D.K. (2000) Art of replacing craniofacial bone defects. Yonsei Medical Journal, 41, 756-765.

[33] Friedenstein, A.J. (1990) Osteogenic stem cell in bone marrow. Journal of Bone and Mineral Research, 7, 243272.

[34] Azami, M., Moosavi, M.J., Baheiraei, N., Moztarzadeh, F. and Ai, J. (2011) Preparation of a biomimetic nanocomposite scaffold for bone tissue engineering via mineralization of gelatin hydrogel and study of mineral transformation in simulated body fluid. Journal of Biomedical Materials Research, 100A, 1347-1355. 